being made that they are emitted by biological substances in certain stages of development. It is difficult to see how the authors could have gone further than they have in their efforts to prove or disprove the existence of these rays. Every precaution in the avoidance of errors and a wide range of material and methods of detection have been employed. In spite of this, all the attempts have yielded negative results. Neither biological nor physical detectors gave any indication that a measurable ultra-violet radiation is given out by typical 'mitogenetic senders'. It is a sobering reflection that no fewer than six hundred papers have been published on this subject.

\section{Potato Synonyms}

THE report of the work of the Potato Synonym Committee during 1936, recently published, forms a striking contrast to those issued in the early years of the Committee's activities. Whereas in former years a considerable proportion of varieties examined proved to be no more than established varieties under new names, in 1936 all but two were found to be distinct. A great reduction is also recorded in the number of synonyms which continue to be offered in seedsmen's catalogues. The improvement in this respect has been continuous, and as a result of direct correspondence, with few exceptions seedsmen throughout Great Britain now intend to list varieties only under their established names. It should be pointed out, however, that Cherub, Early Favourite and Cleadon Park are identical with Duke of York, Sharpe's Express and King Edward VII (red type) respectively, and that although Midlothian Early and Sir John Llewellyn still appear in some catalogues, they are identical with Duke of York and Eclipse. Dr. Salaman and his Committee are to be congratulated on the outcome of their work. At one time it was not generally appreciated, but we can say to-day that seed growers and buyers alike recognize the value of the efforts made to protect their interests by reducing the many names under which potatoes have in the past been sold. Copies of the report for 1936 may be obtained on application to the Secretary, National Institute of Agricultural Botany, Huntingdon Road, Cambridge.

\section{The Royal Society of Arts}

THE annual report of the Council of the Royal Society of Arts refers to the establishment of the distinction of Designer for Industry (D.I.) of the Royal Society of Arts as indicating the Society's continued efforts to raise the status of the British artist in industry. Other examples of its interest in this direction are the travelling bursary of $£ 100$ offered to art teachers, and the decision to revive on new lines the annual competition of industrial designs which was held from 1924 until 1933. It is hoped that the first of the new competitions will be held in 1938 for the textile industry, and that they will in due course be extended to other branches of industry. The Albert Medal of the Society for 1937 was awarded to Lord Nuffield "for services to industry, transport and medical science". Fifteen silver medals were awarded for papers read before the Society during the current session. Entries for the ordinary examinations of the Society in 1937 numbered 75,372, and the total number of papers applied for in all the examinations was 93,497. An important innovation under the Thomas Gray Memorial Trust was the decision to award a number of prizes to stimulate and assist the education of apprentices and deck boys. Prizes to the value of $£ 100$ were awarded during the year under the Trust for essays and inventions connected with the science and practice of navigation.

\section{A New Garden Periodical}

THE first number of Gardening made its appearance on October 15. It ministers well to the increasing popularity of the small garden, and scientific processes are portrayed in simple language. Mention may be made of "Secrets of Dutch Bulb Raising" by Kurt Lubinski, and "Wild Trees in the Garden" by Richard St. Barbe Baker. There are, in addition, more general articles on garden design, plant pests and beneficial insects, the storage of vegetables and fruit, manuring, and many other practical problems. Gardening is a fortnightly journal, price $4 d$., and is published by Messrs. Condé Nast Publications, Ltd., 1 New Bond Street, London, W.1.

\section{Aerial Protection in Belgium}

The Ministry of the Interior in Belgium has organized a graduate school of aerial protection in Brussels for physicians, pharmacists, chemists and engineers. A library has been formed to collect international documentation on the subject, and it is anticipated that practical research laboratories will be established. The programme comprises the following features : international legislation, general and special chemistry, general and special pathology, therapeutics, procedures of identification and dosage, principles of individual and collective protection and general organization for protection.

\section{Ramsay Memorial Fellowship}

The following awards of new memorial fellowships for the year 1937-38 have recently been made : A. E. Alexander, a British fellowship of $£ 300$, tenable for two years, at the University of Cambridge ; T. P. Hughes, a British fellowship of $£ 300$, tenable for one year, at the University of Cambridge; Dr. E. de Salas, a fellowship of $£ 300$, tenable for one year, at University College, London; Dr. E. C. Stathis, a Greek fellowship, tenable at University College, London; Hazime Oosaka, a Japanese fellowship, tenable for two years, at University College, London; Dr. M. C. F. Beukers, a Netherland fellow. ship of $£ 300$, tenable for one year, at the Imperial College of Science and Technology, London; Dr. J. J. Hermans, a Netherland fellowship, tenable at University College, London. The Glasgow fellowship held by Dr. R. R. Gordon at University College, London, has been renewed. 